\title{
Intracavity drainage for bullous, emphysematous lung disease: experience with the Brompton technique
}

\author{
G E VENN, P R WILLIAMS, P GOLDSTRAW
}

From Brompton Hospital, London

ABSTRACT Twenty two operations have been performed on 20 patients for the relief of symptoms due to bullous lung disease. Open intubation drainage of the bullae was used in all patients, the $=$ technique initially devised by Monaldi for the treatment of intrapulmonary tuberculous abscesses $\vec{\square}$ having been modified. Three patients died after surgery. Mortality was associated with low preoperative $\mathrm{FEV}_{1}$ (median $350 \mathrm{ml}$ ) and higher preoperative arterial carbon dioxide tension $\left(\mathrm{PaCO}_{2}\right)^{\mathbb{\Phi}}$ (median $7.8 \mathrm{kPa}$ ). Symptomatic improvement was reported by 16 of the remaining 17 patients and was maintained over a median follow up period of 1.6 years. This was accompanied by objective improvement in lung function with a $22 \%$ median improvement in $\mathrm{FEV}_{1}$, an $11 \%$ median reduction ${ }_{\infty}^{\circ}$ in total lung capacity, and a $26 \%$ median reduction in residual volume. In one patient symptoms were unchanged after surgery. The technique described provides a simple method for decompressingo bullae by means of a minimally invasive surgical procedure. It also allows for the treatment of further bullae at a later date by closed intubation under local anaesthetic. It has proved a suitable approach for all but those with the poorest lung function and is now our treatment of choice.

\section{Introduction}

Dominant bullae are well recognised in association with advanced and generalised emphysematous lung disease. Various surgical techniques have been developed in an attempt to excise the dominant bullae, to allow any underlying compressed and potentially functional lung tissue to re-expand. Techniques that have been used include simple ligation, plication, and segmental or lobar resection, though none of these is ideal. Many patients benefit from surgery, sometimes dramatically; but it has sometimes proved difficult to equate symptomatic improvement with improvement in respiratory function.

Patients referred as potential candidates for surgery frequently have substantial respiratory impairment and surgery is therefore not without risk, from sputum retention, pneumonia, and respiratory failure. Mortality in some series has been as high as $26 \%$. $^{\prime}$

Intracavity intubation and drainage, initially introduced in 1938 by Monaldi to drain pulmonary

Address for reprint requests: Mr P Goldstraw, Department of Thoracic Surgery, Brompton Hospital, London SW3.

Accepted 26 September 1988 cavities after tuberculous infection, ${ }^{2}$ was later adapted for the treatment of any localised pyogenic intrapulmonary abscess ${ }^{34}$ and Monaldi's personal series of cases exceeded $2000{ }^{5}$ The technique has more recently been advocated for the treatment of bullous $-\dot{-}$ emphysema. ${ }^{6-8}$

Techniques using intracavity intubation have potential advantages for the treatment of bullous disease. No lung tissue is removed, and this is impor-o tant for patients with generalised and progressive lung disease; moreover, emphysematous lung tissue is difficult to suture. In addition, the limited incision and brief anaesthesia needed for the procedure are better $\Omega$ tolerated by patients with poor lung function. N

The technique described was originally devised for ${ }_{\mathrm{C}}^{N}$ patients whose lung function was thought too poor to 0 allow major thoracotomy and formal excision of the bullae. We have been anxious to explore the limits of the technique and have therefore treated "all comers." ?

\section{Methods}

PATIENTS AND INVESTIGATIONS

Twenty two operations have been performed on $20 \frac{\mathrm{Q}}{\sigma}$ patients, of whom 12 were male and eight female; the median age was 56 (range 43-71) years. In all cases theo 


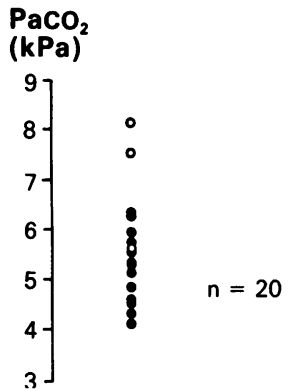

(a)

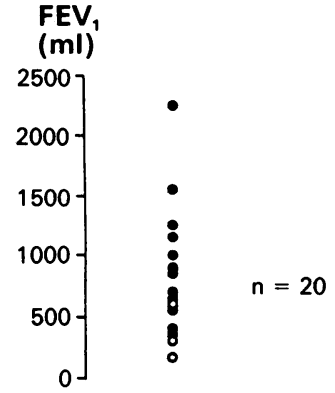

(b)

Fig 1 Preoperative arterial carbon dioxide tension $\left(\mathrm{PaCO}_{2}\right)$ and $F E V$, for survivors (O) and those dying (O) after surgery. $p<0.05$, (a) and $(b)$.

indication for surgery was debilitating dyspnoea in the presence of dominant discrete bullous disease. All patients had simple respiratory function tests, including routine spirometry and measurement of arterial blood gas tensions, and in most cases more detailed respiratory function tests and assessment of lung volumes were available. All patients had routine posteroanterior and lateral chest radiography, and more recently computed tomography has been used for assessing multiple bullae and planning surgery. Computed tomography may also allow accurate three dimensional measurement of the bullae, both before and after surgery. The earlier patients in the series did not have computed tomography evaluation of bulla size.

\section{SURGER Y}

We have modified the original technique of Monaldi, incorporating suggestions from other surgeons. We use a single stage technique, as advocated by MacArthur, ${ }^{6}$ instilling sclerosant directly into the bulla to produce rapid contraction and fibrosis within the bulla (McCluskie, personal communication) and inducing pleurodesis to minimise the immediate effect of any air leak in the pleural space. The latter will allow other bullae to be treated later by percutaneous

drainage under local anaesthesia. We were initially concerned that the intrapulmonary insufflation of sclerosant might produce bronchoconstriction as bullae may be ventilated by a major bronchus, but this has not occurred.

\section{Operative procedure}

A limited thoracotomy $(10 \mathrm{~cm})$ is performed, to resect a portion of the underlying rib. The site of the incision is determined according to the site of the bulla and the disposition of adjacent compressed lung tissue. We aim to position the base of the decompressed bulla so that it is as close to the incision as possible. The pleura is opened and the bulla incised, and two concentric polypropylene purse string sutures are inserted around this incision. The interior of the bulla is inspected and the septa perforated to allow free communication with adjacent loculae or bullae. Iodised talc is liberally insufflated into the bulla cavity. A large Foley catheter (size $32 \mathrm{FG}$ ) is inserted into the cavity via a separate stab incision in the chest wall, and the balloon is inflated with $30-40 \mathrm{ml}$ air to function as a self retaining intrapulmonary drain. The purse string sutures are secured. The remaining free pleural cavity is liberally insufflated with talc to obtain a thorough postoperative pleurodesis. An intrapleural drain is inserted at the most dependent part of the pleural space and the wound closed. Slight traction on the intrapulmonary drain causes the bulla to lie adjacent to the chest wall. Postoperatively the Foley catheter, lying within the bullae, remains on free underwater seal drainage. The air leak from this drain is frequently brisk. The intrapleural drain remains on underwater seal suction at 2-5 $\mathrm{kPa}$. It is removed when any air leak has stopped, usually within 48 hours. The Foley catheter is removed at 8 days, irrespective of residual air leak. The patient is able to mobilise during this time with a single underwater seal drain carried in a suitable transporter. This period allows a secure bronchocutaneous fistula to form. After removal of the drain this bronchocutaneous fistula spontaneously closes within the ensuing 24-48 hours, after which the patient is discharged from

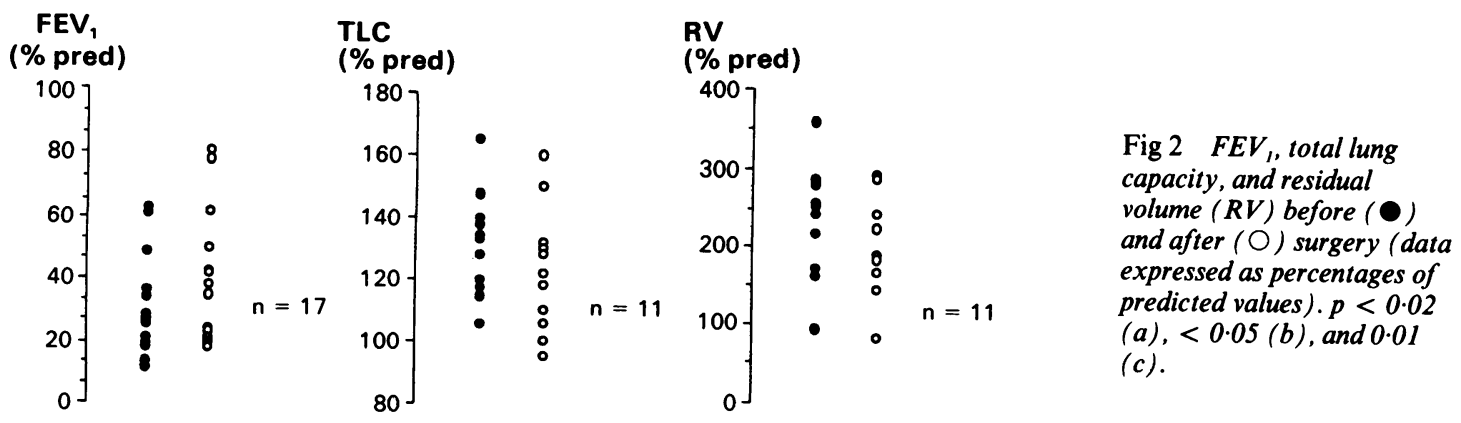

(a)

(b)

(c) 


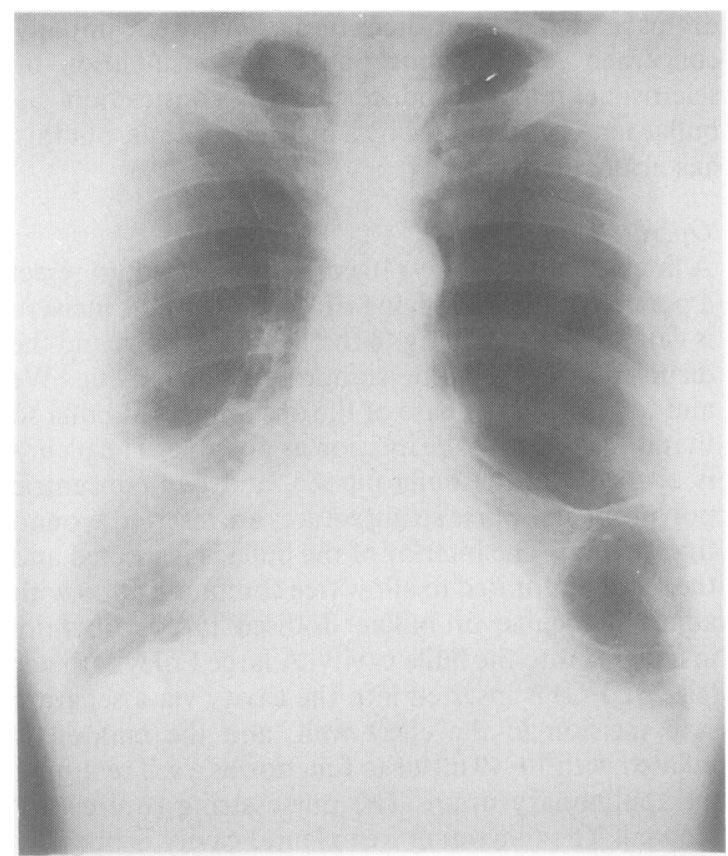

Fig 3 Preoperative chest radiograph from a patient with bilateral bullous disease.

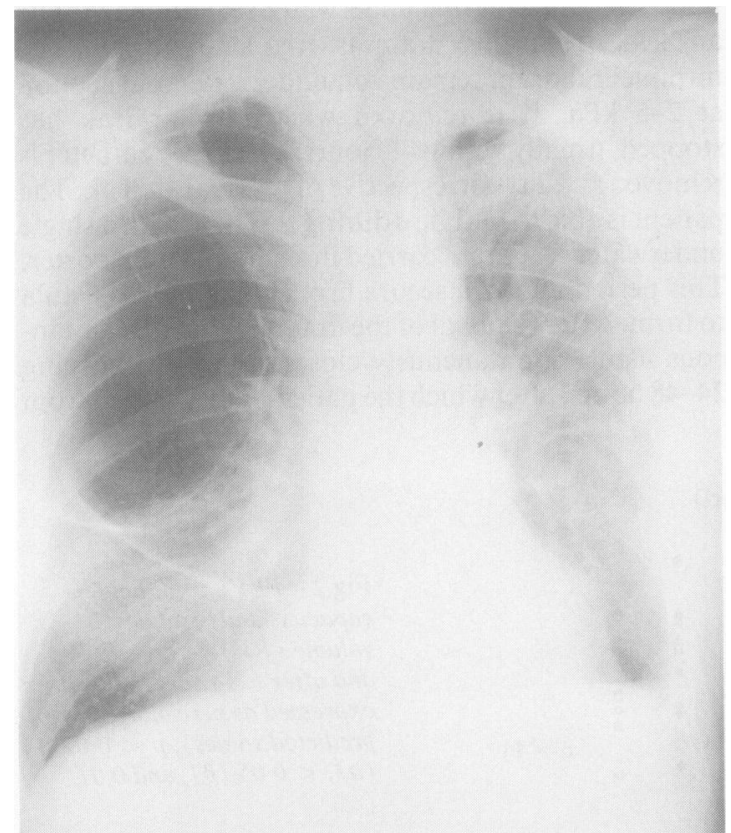

Fig 4 Postoperative chest radiograph from the same patient after left sided surgery. hospital.

The data were not normally distributed. Paired data were analysed with the Wilcoxon signed rank test and unpaired data with the Mann-Whitney U test.

\section{Results}

Three of the 20 patients died in the postoperative $\overrightarrow{\vec{\omega}}$ period. Two of the deaths were due to progressive $O$ respiratory failure and the third to staphylococcal $\vec{x}$ septicaemia.

The preoperative $\mathrm{FEV}_{1}$ ranged from 220 to $2130 \stackrel{\omega}{\omega}$ (median value 740 ) $\mathrm{ml}$. Fifteen patients had an $\mathrm{FEV}_{1}, \overrightarrow{0}$ of less than 1 litre. The median $\mathrm{FEV}_{1} / \mathrm{FVC}$ ratio was $@$ $34 \%$ (range $17-50 \%$ ). The preoperative arterial carbon dioxide tension $\left(\mathrm{PaCO}_{2}\right)$ ranged from $4 \cdot 2$ to $8 \cdot 2 \stackrel{\mathrm{J}}{工}$ $\mathrm{kPa}$ with a median value of $5 \cdot 2 \mathrm{kPa}$. Patients who died after surgery were more likely to have had a low $\mathbb{D}$ preoperative $\mathrm{FEV}_{1}\left(\mathrm{p}<0.05^{*}\right)$ and a higher $\stackrel{\mathbb{}}{3}$ preoperative $\mathrm{PaCO}_{2}\left(\mathrm{p}<0.05^{*}\right)$ (fig 1). The two patients dying of respiratory failure had severe impairment of lung function before operation with $F E V_{1} \vec{\oplus}$ values of 220 and $350 \mathrm{ml}$, the former having $\alpha_{1}$. antitrypsin deficiency. In the remaining 17 patients there was a $22 \%$ median improvement in $\mathrm{FEV}_{1} \leq$ ( $p<0.02) \dagger$, fig 2 ), an $11 \%$ median reduction in total lung capacity expressed as a percentage of the predicted value ( $p<0.05 \dagger$, fig 2 ), and a $26 \%$ median $\mathbb{Q}$ reduction in residual volume $(\mathrm{p}<0.01 \dagger$, fig 2$)$. The $\vec{F}$ residual volume (expressed as a percentage of the total $\frac{}{3}$ lung capacity) fell from a median of $69 \%$ to $59 \%$ after surgery $(\mathrm{p}<0.05 \dagger)$. Radiological improvement was seen in all patients (figs 3 and 4). Subjective improvement was reported by all but one patient, who음 remained unchanged. The improvement has been $\stackrel{\infty}{\times}$ maintained so far for all but two patients over a 0 median follow up period of 1.6 years. In both patients deterioration was attributable to formation of furthero bullae. Percutaneous drainage was performed again in both cases, under local anaesthesia, with additionalo symptomatic improvement.

\section{Discussion}

The presence of bullous disease in association with $N$ generalised emphysema is well recognised and N presumably represents what Sir John Floyer waso describing as the "cystic alterations in the lungs in broken winded horses" in $A$ Treatise of the Asthma in 1717. ${ }^{9}$ In this work Floyer suggested invasive treat- $-?$ ment for the condition.

The cure of the broken wind cannot easily be projected any other way but by a paracentesis in the thorax, for if the external air be admitted, it will

*Mann-Whitney test; †Wilcoxon rank sum test. 
compress the flatulent tumour and through the same hole a styptic and carminative hydromel be injected, to restore by its stypticity the tone of the membranes, and discuss by its aromatic acrimony the windy spirits or air retained in the lungs.

The surgical treatment of such bullae was not popularised until the early to middle part of this century. Such surgery has typically been "bullectomy": formal resection of lung incorporating the bullae, the resection ranging in magnitude from a small wedge of pulmonary tissue to one or occasionally more lobes. Occasionally a bulla presents itself as a discrete "cyst" on a narrow based pedicle, allowing simple ligation and removal without the excision of any underlying pulmonary tissue. This usually occurs without associated emphysema. The mortality associated with surgery has ranged from $2 \%$ to $26 \% .^{16-1315-17}$ Death is usually due to progressive postoperative respiratory failure, precipitated by pulmonary infection in patients with poor lung function. Their condition is aggravated by the occurrence of a persistent air leak and the attendant immobilisation after pulmonary resection, to which these patients are particularly prone because of their underlying emphysema. For this reason some authors have advocated the use of Teflon pledgeted sutures for such tissue. ${ }^{18}$

Patients presenting with bullae usually have moderate or severe respiratory impairment, as in our own series, with a low FEV 1 and other evidence of airflow obstruction. Such patients cannot usually tolerate any further reduction in their respiratory performance, however brief. The best results from surgery, in terms both of mortality and of symptoms, have been when bullae have been removed or decompressed without resection of lung tissue or alternatively when the resection encompasses an entire lobe. . $^{34813}$

The assessment of patients for surgery has proved difficult. Earlier reports noted that the best results were in those patients in whom the bulla exceeded one third of the volume of the affected hemithorax and whose respiratory function was not complicated by generalised emphysema. ${ }^{7141516}$ Wesley $^{10}$ advocated preoperative indium perfusion scanning to identify patients with large, discrete, perfusion defects as a sign of larger, discrete bullae. Other techniques have been advocated. Logan (personal communication) found bronchography of value in assessing the distribution of emphysema within a lobe and the compression of adjacent lung tissue. Most surgeons have relied on posteroanterior and lateral chest radiographs, choosing to operate only on patients with radiographic evidence of parenchymal "compression" adjacent to the bulla. Latterly, in our own series, we employed computed tomography and this allowed visualisation of intrathoracic bullous disease far superior to that afforded by conventional radiology. It will distinguish large discrete bullae from more generalised emphysema, where bullous surgery is often inappropriate and unrewarding.

Many observers have had difficulty in equating the subjective improvement reported by patients after surgery for bullous disease with improvement in the results of conventional lung function tests. ${ }^{101141617}$ Some sceptics argue that this indicates the placebo effiect of surgery in this condition. The alternative suggestion, that we cannot easily define and measure the cause of dyspnoea in these patients, may be more realistic. In our own series subjective improvement correlated well with improved spirometric results and reduction in total lung capacity and residual volume. The absence of any improvement in arterial blood gas tensions and carbon monoxide transfer factor would argue against the relief of lung compression as the cause of the subjective improvement. The reduction in lung volumes would cause a reduction in the work of breathing and this, combined with a reduction in the sensation of discomfort, possibly from chest wall stretch receptors as a result of the reduction in chronic hyperinflation of the chest, may play an important part in the symptomatic improvement reported by these patients.

Monaldi's technique of closed intubation drainage, initially used for the treatment of post-tuberculous and subsequently other localised pyogenic abscess cavities, has been advocated by others for the treatment of bullous disease.$^{67}$ It was initially described as a two stage procedure. The first stage was to obtain a pleurodesis with the extrapleural insertion of an iodine soaked pack, ${ }^{67}$ which was subsequently removed, the wound being allowed to heal before the second stage of catheter insertion and suction drainage of the bulla. We have combined these two stages to allow a satisfactory pleurodesis and drainage of the bulla to be carried out at the same time. The technique has the great appeal of requiring a very limited surgical approach and avoids resection of underlying lung tissue, which is important for these patients with limited respiratory reserve. The use of computed tomography has greatly facilitated the selection of patients, allowing exclusion of those with generalised emphysema accompanying their bullous disease, in whom surgery produces poor results. It has also allowed better preoperative planning of the surgical approach by localising underlying compressed pulmonary tissue. This enables the surgical incision to be positioned to allow the base of the bulla and the intracavity drain to lie adjacent to the chest wall after decompression. The technique was valuable in treating the two patients who presented after their initial surgery with further bulla formation. The pleurodesis 
obtained at the initial operation allowed intubation and drainage of the new bullae percutaneously under local anaesthesia, without risk of pneumothorax.

We have attempted to push this technique to the limit and now recognise that, although highly suitable for patients with poor respiratory function, two of the three patients who died had respiratory function (FEV, 220 and $350 \mathrm{ml}$ ) that was too poor to allow even minimally invasive surgery. The percentage improvement in lung function provided by this technique would have left these patients still housebound and bedridden. We now accept a preoperative $F E V_{1}$ of $500 \mathrm{ml}$ as a minimum prerequisite for surgery. This may seem somewhat arbitrary; but we believe that this level of lung function offers safe surgery, and the order of improvement to be expected by this technique will provide an important improvement in the quality of life of such patients.

\section{References}

1 Hugh Jones P, Ritchie BC, Dollery CT. Surgical treatment of emphysema $\mathrm{Br}$ Med J 1966;i:1133-8.

2 Monaldi V. Tentativi di aspirazione endocavitaria nelle caverne tuberculari del polmone. Lotta Contro la Tuberculosi 1938;9:910-1.

3 Monaldi V. Endocavitary aspiration in the treatment of lung abscess. Dis Chest 1956;29:193-201.

4 Head JR. Intracavity (Monaldi) suction. J Thorac Surg 1946;15:153-61.

5 Monaldi V. Endocavitary aspiration: its practical application. Tubercle 1946;28:223-8.

6 MacArthur AM, Fountain SW. Intracavity suction and drainage in the treatment of emphysematous bullae. Thorax 1977;32:668-72.

7 Head JR, Avery EA. Intracavitary suction (Monaldi) in the treatment of emphysematous bullae and blebs. $\stackrel{\mathbb{\perp}}{\varnothing}$ $J$ Thorac Cardiovasc Surg 1948;18:761-76.

8 Head JM, Head LR, Hudson TR, Head JR. The surgical treatment of emphysematous blebs and localised $\vec{O}$ vesicular and bullous emphysema. $J$ Thorac Cardiovasc Surg 1960;40:443-60.

9 Floyer JA. A treatise of the asthma. 2nd ed. London:1717.

10 Wesley JR, Macleod WM, Mullard KS. Evaluation and $\times$ surgery of bullous emphysema. $J$ Thorac Cardiovasc $\vec{c}$ Surg 1972;63:945-55.

11 Knudson RJ, Gaensler EA. Surgery for emphysema. Ann Thorac Surg 1965;21:332-62.

12 Sung DT, Spencer Payne W, Black LF. Surgical

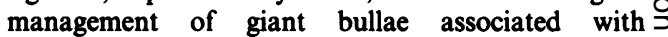
obstructive airway disease. Surg Clin North Am1973;53:913-20.

13 Potgieter PD, Benatar SR, Hewitson RP, Ferguson AD. Surgical treatment of bullous lung disease. Thorax 1981;36:885-90.

14 Rogers RM, DuBois AB, Blakemore WS. Effect of removal of bullae on airway conductance and conduc- $\vec{\varphi}$ tance volume ratios. J Clin Invest 1968;47:2569-79.

15 Pearson MG, Ogilvie C. Surgical treatment of emphysematous bullae: late outcome. Thorax 1983;38:134-7.

16 Fitzgerald MX, Keelan PJ, Cugell DW, Gaensler EA. Long term results of surgery for bullous emphysema. J Thorac Cardiovasc Surg 1974;68:566-87.

17 Pride NB, Hugh-Jones P, O'Brien EN, Smith LA. Changes in lung function following the surgical treatment of bullous emphysema. $Q J$ Med 1970;39:49-69.

18 Parmar JM, Hubbard WG, Matthews HR. Tefion strip pneumostasis for excision of giant emphysematous bullae. Thorax 1987;42:144-8. 